Albert Wijaya, Riris Loisa: Bauran Komunikasi Pemasaran dalam Mempertahankan Loyalitas Pelanggan (Studi Kasus Resto Ahwa)

\title{
Bauran Komunikasi Pemasaran dalam Mempertahankan Loyalitas Pelanggan (Studi Kasus Resto Ahwa)
}

\author{
Albert Wijaya, Riris Loisa \\ albertw.ik@stu.untar.ac.iddan riris@fikom.untar.ac.id
}

Fakultas Ilmu Komunikasi Universitas Tarumanegara

\begin{abstract}
The purpose of this research is to find out how to develop marketing and development communication strategies in maintaining the loyalty of Ahwa Resto customers. The technical data analysis that I use for this study is based on the stages of the qualitative data analysis process as stated by Moleong is data reduction. The study used the method of interview with the Ahwa restaurant owner. Research data obtained from the interview. The theory used in this study is the concept of marketing communication strategies according to Wenats. The conclusion of this study is the marketing communication strategy used by Ahwa Restaurant in accordance with the marketing communication mix concept.
\end{abstract}

Keywords: Mix marketing communications, development, customer loyalty

\begin{abstract}
Abstrak
Tujuan penelitian ini adalah mengetahui bauran komunikasi pemasaran dan pengembangan dalam mempertahankan loyalitas pelanggan Resto Ahwa. Teknis analisis data yang penulis gunakan untuk penelitian ini adalah reduksi data. Penelitian menggunaakan metode wawancara dengan narasumber pemilik restoran Ahwa. Data penelitian yang diperoleh bersumber dari wawancara. Teori yang digunakan dalam penelitian ini adalah konsep strategi komunikasi pemasaran menurut Wenats. Kesimpulan dari penelitian ini adalah strategi komunikasi pemasaran yang digunakan oleh Restoran Ahwa sesui dengan konsep bauran komunikasi pemasaran .
\end{abstract}

Kata kunci: Bauran komunikasi pemasaran, pengembangan, loyalitas pelanggan

\section{Pendahuluan}

Pertumbuhan industri kuliner di Indonesia akan tetap baik bahkan terus mengalami kenaikkan pada tahun-tahun mendatang. Industri kuliner masih akan tetap menjadi andalan sektor industri pengolahan non migas. Pertumbuhan industri kuliner tetap tumbuh dan menjadi sektor andalan karena didukung oleh kuatnya permintaan di dalam negeri, yang diakibatkan oleh semakin meningkatnya konsumen kelas menengah di dalam negeri. Semakin besar dan terbukanya pasar di dalam negeri yang menjadi daya tarik, namun akan menimbulkan ancaman masuknya produk sejenis dari negara lain.

Etnis Tionghoa mendominasi perekonomian dan daftar orang terkaya di Indonesia. Menurut Forbes (2017) bahwa orang terkaya di Indonesia merupakan Budi dan Hartono yaitu pengusaha beretnis Tionghoa dan disusul oleh Eka Tjipta Widjaja yang juga merupakan pengusaha beretnis Tionghoa. Masih banyak pengusaha beretnis Tionghoa lainnya yang mendominasi dalam jajaran orang terkaya di Indonesia serta mendominasi perekonomian di Indonesia. 
Bauran komunikasi pemasaran atau marketing mix merupakan kombinasi variable atau kegiatan yang merupakan inti dari sistem pemasaran, variabel yang dapat dikendalikan oleh perusahaan untuk mempengaruhi tanggapan konsumen dalam pasar sasarannya. Bauran komunikasi pemasaran (marketing communication mix) merupakan penggabungan dari lima model komunikasi dalam pemasaran, yaitu: advertising, sales promotion, public relations, personal selling, dan direct marketing

\section{Metode Penelitian}

Metode yang digunakan dalam penelitian ini merupakan jenis penelitian studi kasus. Menurut Emzir (2012) penelitian studi kasus adalah suatu penelitian kualitatif yang berusaha menemukan makna, menyelidiki proses, memperoleh pengertian dan pemahaman yang mendalam dari individu, kelompok atau situasi. Dalam studi kasus dapat menggunalan berbagai teknik termasuk wawancara, observasi, maupun pemeriksaan dokumen dan artfak dala mpengumpulan data.

Sementara itu, menurut Bungin (2015), key informan adalah orang yang terlibat langsung dalam situasi sosial tertentu yang sarat informasi dan memahami persoalan secara mendalam. Informan yang penulis pilih adalah Marvianto, pengurus. Penulis memilih narasumber tersebut sebagai informan, karena narasumber yang cukup berperan dan berpengaruh dalam mengurus Resto Ahwa sehingga penulis dapat memperoleh informasi yang asbsah mengetahui kebenaran informasinya.

Dalam melakukan penelitian ini penulis melakukan beberapa teknik dalam pengumpulan data diantaranya dalah wawancara, observasi, dokumentasi.

1. Wawancara

Wawancara yang dipilih yaitu wawancara mendalam yaitu suatu cara mengumpulkan data langsung atau bertatap muka dengan informan untuk mendapatkan data yang mendalam dan lengkap (Kriyantono, 2010).

2. Observasi

Observasi atau pengamatan menurut Burhan Bungin adalah kegiatan manusia sehari-hari menggunakan pancaindra mata sebagai alat bantu utamanya selain pancaindra lainnya seperti telinga, penciuman, mulut dan kulit.

3. Dokumentasi

Menurut Ruslan (2014) dalam buku Metode Penelitian Public Relations dan Komunikasi, data sekunder adalah data penelitian yang diperoleh peneliti secara tidak lagsung melalui media perantara, umumnya berupa bukti, catatan, atau laporan historis yang disusun dalam bentuk arsip atau dokumen.

Teknik analisis data yang penulis gunakan untuk penelitian ini bedasarkan pada tahapan proses analisis data kualitatif sebagaimana dinyatakan oleh Moleong (2014) adalah reduksi data. Adapun data yang direduksi antara lain seluruh data mengenai permasalahan penelitian dan kemudian dilakukan penggolongan ke dalam beberapa bagian yang akan menjawab setiap bagian rumusan masalah. Perolehan data yang dianggap tidak relevan atau tidak diperlukan dalam penelitian ini tidak akan dimasukan ke dalam hasil. 
Albert Wijaya, Riris Loisa: Bauran Komunikasi Pemasaran dalam Mempertahankan Loyalitas Pelanggan (Studi Kasus Resto Ahwa)

\section{Hasil dan pembahasan}

Resto Ahwa didirikan besar dan berkembang. Resto ini berkembang cukup pesat. Kini, tahun 2019, Resto Ahwa sudah mempunyai enam ruko. Salah satu restonya ada Jl. Tubagus Angke, Blok C1A No. 19, Jelambar, Komplek Taman Duta Mas, Jakarta. Resto di lokasi ini terdiri dari dua lantai yang dapat menampung 200300-an pelanggan.

Resto Ahwa sekarang merupakan salah satu resto Chinese Food yang cukup terkenal di Jakarta Barat dan memiliki cabang di Muara Karang. Selain menyajikan chinese food sebagai hidangan utama, hidangan lain yang ditawarkan adalah nasi campur khas Ahwa. Nasi campur Ahwa tersebut disajikan dengan daging babi merah, babi panggang, ayam rebus atau ayam panggang dan juga bebek panggang serta nasi hainan. Di samping itu terdapat counter bakpao dan asinan jambu yang terletak di bagian luar resto.

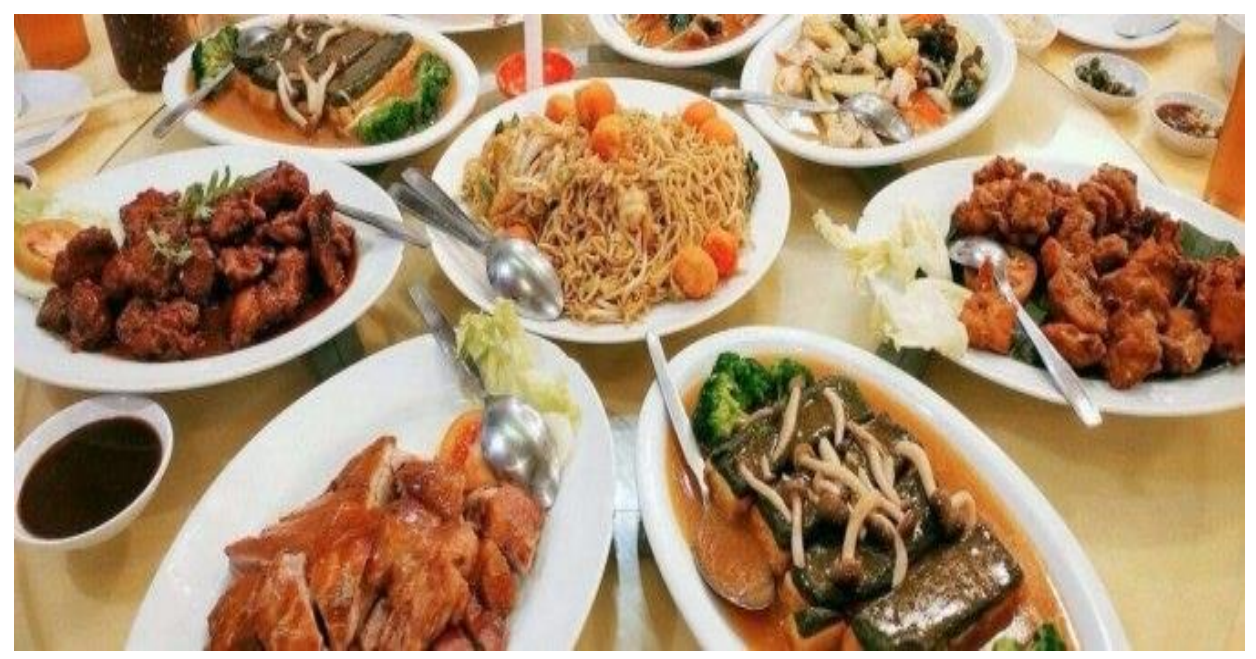

Gambar 1. Menu Makanan Resto Ahwa

Sumber : Dokumen Resto Ahwa (2019)

Menu masakan di Resto Ahwa adalah cha siew, babi panggang merah, samcan, lapchiong, ayam panggang, kerapu tim Tom Yam, Cumi Goreng Mentega, Ayam Goreng Kering, Asparagus cah Terasi, Ayam Saos Mangga, Tahu ala Thai, Ikan Kakap Tim Tom Yam.

Salah satu karakteristik utama dari masakan tradisional China adalah menggunakan teori "yin" dan "yang" sebagai pertimbangan dalam mempersiapkan masakan. Secara singkat, teori yin dan yang menyebutkan bahwa fenomena alam memiliki hubungan yang berkebalikan dan saling menutupi satu sama lain. Secara umum, masakan yang mengandung banyak air disebutkan sebagai "bersifat dingin" atau yin. Jenis masakan tersebut kebanyakan direbus atau dikukus. Makanan yang memiliki banyak energi, secara khususnya lemak, disebutkan sebagai "bersifat panas" atau yang. Kebanyakan jenis makan tersebut dibakar atau digoreng.

Berdasarkan analisis lingkungan eksternal dan internal, diperoleh hasil berupa nilai matriks yang menentukan posisi komunikasi pemasaran dan pengembangan bisnis Resto Ahwa untuk dijadikan acuan dalam memformulasikan alternatif strategi pemasaran. 


\section{Komunikasi Pemasaran}

Restoran Ahwa menggunakan strategi komunikasi pemasaran dan pengembangan bisnis promosi yang dilakukan melalui komunikasi langsung yang artinya langsung dari pihak resto Ahwa dengan pelanggan. Dengan komunikasi tersebut pelanggan akan merasa kalau restoran resti ini peduli dengan pelanggan.Apalagi sebagain besar pelanggan Resto Ahwa adalah orang tua yang masih kurang mengerti menggunakan media sosial. Dengan kondisi ini Resto Ahwa masih menggunakan saluran pemasaran yang dimilikinya. Hasil ini didukung oleh jawaban wawancara yang menyatakan bahwa:

"Tidak, tetapi kalau yg di cabang ada tapi kita sangat jarang menggunakan media sosial, karena menurut tapi kurang efektif untuk restoran. Karena pasar tapi itu bapak" atau ibu" yang masih kurang mengerti menggunakan media sosial"

\section{Pengembangan}

Strategi pengembangan bisnis pada Resto Ahwa adalah dengan cara berkomunikasi langsung kepada pelanggan untuk memberikan diskon pada hari Senin sampai jumat sebesar 10\%, dan Sabtu sampai Minggu memberikan diskon 10\% bagi yang mempunyai member Restoran Ahwa. Diskon atau potongan harga merupakan salah satu pengembangan strategi pemasaran produk dalam bisnis yang terbukti masih efektif hingga saat ini.

Menawarkan diskon adalah sebuah strategi yang bisa meningkatkan penjualan dan membawa pelanggan baru. Salah satu keuntungannya adalah potongan harga membuat pelanggan merasa senang. Ketika seseorang menerima pesan secara langsung dari pihak Resto Ahwa jika mereka mendapatkan kupon atau diskon, maka mereka menjadi lebih senang dan merasa lebih dihargai.

Hal itu dapat menguntungkan dalam jangka panjang jika perasaan itu tersebut dapat diasosiasikan dengan komunikasi langsung dari pihak Resto Ahwa. Melalui komunikasi langsung, diskon atau potongan harga tersebut menjadi strategi pemasaran produk yang efektif. Diskon ini diperoleh jika pelanggan menjadi member resto. Dengan begitiu Pelanggan pun merasa dihargai apabila diberikan potongan tersebut. Hasil ini didukung oleh jawaban wawancara yang menyatakan bahwa: "Senin sampai jumat diskon $10 \%$, sabtu dan minggu kita memberi diskon $10 \%$ bagi yang mempunyai member restoran Ahwa"

\section{Loyalitas pelanggan}

Cara Resto Ahwa membuat pelanggan tertarik adalah dengan meningkatkan dan mempertahankan kualitas pelayanan dan cita rasa makanan. Kinerja Restoran yang berorientasi kepada konsumen perlu dipertahankan baik dari segi pelayanan dan kualitas makanan yang dilakukan harus semaksimal mungkin. Kinerja Restoran Ahwa harus dilakukan secara konsisten sehingga memberi hasil loyalitas pelanggan. Hasil ini didukung oleh jawaban wawancara yang menyatakan bahwa:

"Kita meningkatkan kualitas pelayanan dan rasa makanan"

Cara Resto Ahwa membuat pelanggan puas dan datang kembali adalah dengan membuat suasana restoran yang nyaman. Suasana yang dimaksud adalah dengan memutarkan lagu Mandarin dan menciptakan suasana tradisional pada interior. Itu sebabnya Restoran Ahwa membangun halaman depan untuk menjual kuliner jajanan 
Albert Wijaya, Riris Loisa: Bauran Komunikasi Pemasaran dalam Mempertahankan Loyalitas Pelanggan (Studi Kasus Resto Ahwa)

khas tionghoa. Hasil ini didukung oleh jawaban wawancara yang menyatakan bahwa

"Kita membuat suasana restoran senyaman mungkin mengunakan musik lagu mandarin dan membuka stand mainan dan makanan ringan di depan restoran dan mainan" untuk bagi orang tua yang membawa anak kecil agar anak mereka puas juga. Dan juga setiap pelanggan selesai makan kita memberikan hidangan penutup berupa buah-buahan"

Evaluasi yang dilakukan oleh Resto Ahwa terkait dengan saluran komunikasi pemasaran dengan meningkatkan mutu dan kualitas untuk tetap membuat pelanggan merasa puas dan nyaman. Resto Ahwa juga menawarkan tempat dan suasana dengan konsep modern tetapi tidak menghilangkan suasana tradisional di dalamnya. Hal tersebut dapat dilihat dari aksen-aksen dan elemen-elemen Tionghoa di dalamnya, seperti penggunaan meja bundar, peralatan makan yang berkonsep Tionghoa. Hasil ini didukung oleh jawaban wawancara yang menyatakan bahwa:

"Kita lebih meningkatkan mutu dan kualitas dan konsep tradisional dari pada pemasran di sosial media. Karena dengan mutu yang baik maka orang akan tertarik dan selalu berkunjung disini."

Kegiatan untuk peningkatan pemasaran dan pelayanan merupakan salah satu strategi andalan utama bagi usaha bisnis Resto Ahwa, disamping pengembangan kegiatan usaha yang bertujuan untuk mempertahankan usaha, yaitu menggunakan baner diskon dan mengkomunikasi orang ke orang atau mengiklankan bahwa restoran diskon dan pihak Resto Ahwa menyampaikan kepada pelanggan agar memberi tahu informasi diskon ke orang lain. Restoran Ahwa dengan ini bisa membuat ikatan yang kuat dengan pelanggan seperti melalui pengindividuan dan personalisasi hubungan untuk meningkatkan loyalitas pelanggan. Analisis SWOT pada Resto Ahwa adalah sebagai berikut:

1. Faktor kekuatan (S)

Rasa makanan yang enak dengan nasi campur sebagai menu andalan dan lokasi strategis.

2. Faktor kelemahan (W)

Pemasaran melalui media sosial kurang efektif dan pelayanan pada hari ramai belum terstruktur.

3. Faktor peluang $(\mathrm{O})$

Ramainya pembelian makanan melalui aplikasi online dan teknologi komunikasi bisa menjadi sarana promosi.

4. Faktor ancaman $(\mathrm{T})$

Persaingan dalam usaha makanan sejenis dan adanya ancaman pendatang baru. 
Tabel 1. Rumusan strategi pemasaran (komunikasi bisnis) dengan matriks SWOT untuk mempertahankan loyalitas pelanggan

\begin{tabular}{|c|c|c|}
\hline Faktor Internal & $\begin{array}{l}\text { Faktor kekuatan }(\mathbf{S}) \\
\text { Rasa makanan yang enak dengan } \\
\text { nasi campur sebagai menu andalan } \\
\text { Lokasi strategis }\end{array}$ & $\begin{array}{l}\text { Faktor kelemahan (W) } \\
\text { Pemasaran melalui media sosial } \\
\text { kurang efektif } \\
\text { Pelayanan pada hari ramai belum } \\
\text { terstruktur }\end{array}$ \\
\hline Faktor peluang $(\mathrm{O})$ & & Strategi WO (diversifikasi) \\
\hline $\begin{array}{l}\text { Ramainya pembelian } \\
\text { makanan melalui } \\
\text { aplikasi online } \\
\text { Teknologi komunikasi } \\
\text { bisa menjadi sarana } \\
\text { promosi }\end{array}$ & $\begin{array}{l}\text { Membuat paket promo nasi campur } \\
\text { dengan menu lain melalui aplikasi } \\
\text { online } \\
\text { Memberikan informasi dan promosi } \\
\text { melalui teknologi komunikasi }\end{array}$ & $\begin{array}{l}\text { Mulai bekerjasama dengan } \\
\text { aplikasi online } \\
\text { Meningkatkan penggunaan } \\
\text { teknologi komunikasi untuk } \\
\text { memberikan promosi di hari-hari } \\
\text { yang kurang ramai }\end{array}$ \\
\hline $\begin{array}{l}\text { Faktor ancaman }(\mathbf{T}) \\
\text { Persaingan dalam usaha } \\
\text { makanan sejenis } \\
\text { Ancaman pendatang } \\
\text { baru }\end{array}$ & $\begin{array}{l}\text { Strategi ST (diferensiasi) } \\
\text { Meningkatkan komunikasi dan } \\
\text { mempertahankan cita rasa masakan } \\
\text { yang dihasilkan } \\
\text { Membina dan menjaga hubungan } \\
\text { dengan pelanggan agar loyalitas } \\
\text { pelanggan meningkat }\end{array}$ & $\begin{array}{l}\text { Strategi WT (defensif) } \\
\text { Meningkatkan efektivitas } \\
\text { pemasaran melalui media sosial } \\
\text { untuk mengatasi persaingan } \\
\text { Memperbaiki mutu SDM dan } \\
\text { memperbaiki kualitas pelayanan } \\
\text { terlebih di hari ramai pelanggan }\end{array}$ \\
\hline
\end{tabular}

Formulasi keterangan pada Tabel 4.1 berikut:

a. Strategi S dengan O (S1-S2 kombinasi dengan O1-O2)

Dari hasil analisis diperoleh beberapa formulasi strategi seperti membuat paket promo nasi campur dengan menu lain melalui aplikasi online serta memberikan informasi dan promosi melalui teknologi komunikasi.

b. Strategi S dengan T (S1-S2 kombinasi dengan T1-T2)

Dari hasil analisis strategi, meningkatkan dan mempertahankan cita rasa masakan yang dihasilkan Resto Ahwa untuk meningkatkan pelanggan dan loyalitas pelanggan. Hasil ini didukung oleh jawaban wawancara yang menyatakan bahwa:

"masih belum ada rencana, kita tetap mempertahankan kualitas makanan dan pelayanan."

c. Strategi W dengan O (W1-W2 kombinasi dengan O1-O2)

Dari hasil analisis ini diperoleh strategi untuk mulai bekerjasama dengan aplikasi online dan meningkatkan penggunaan teknologi komunikasi untuk memberikan informasi terutama dalam hal promosi di hari-hari yang kurang ramai. Secara umum, Resto Ahwa memiliki kelemahan, yaitu pemasaran masih kurang optimal. Resto Ahwa memiliki peluang terutama seiring dengan perkembangan zaman yang serba online namun demikian strategi yang dapat dilakukan.

d. Strategi W dengan T (W1-W2 kombinasi dengan T1-T2)

Dari hasil analisis ini diperoleh strategi yaitu meningkatkan efektivitas pemasaran melalui media social untuk mengatasi persaingan yang ketat. Selain itu, yang dapat dilakukan Restoran Ahwa memperbaiki mutu SDM dan meningkatkan kualitas pelayanan terlebih di hari ramai pelanggan. 
Albert Wijaya, Riris Loisa: Bauran Komunikasi Pemasaran dalam Mempertahankan Loyalitas Pelanggan (Studi Kasus Resto Ahwa)

\section{Pembahasan}

Berdasarkan pada hasil analisis dan wawancara dengan pemilik Resto Ahwa diketahui bahwa yang dilakukan Resto Ahwa selama ini cukup baik dimana sudah melakukan komunikasi pemasaran langsung bagi pelanggan untuk meningkatkan loyalitas pelanggan. Hal ini sesuai dengan teori yang dikemukakan oleh Sutisna (2013) yaitu komunikasi pemasaran langsung merupakan usaha untuk menyampaikan pesan kepada publik terutama konsumen mengenai keberadaan suatu produk di pasar.

Membership loyalty program atau program loyalitas pelanggan adalah sebuah program promosi yang dirancang perusahaan untuk menciptakan hubungan jangka panjang yang saling menguntungkan antara perusahaan dengan para pelanggannya sehingga tercipta pembelian terus menerus terhadap sebuah produk atau jasa perusahaan. Program ini sangat penting karena dapat membantu restoran dalam mempertahankan pelanggan, agar menjaga pelanggan tidak mudah tergiur oleh tawaran kompetitor serta meningkatkan kepuasan pelanggan. Jika berhasil menjaga hubungan baik dengan pelanggan, maka perusahaan juga dapat menjaga kestabilan nilai penjualan, margin maupun keuntungan.

Strategi yang dapat diterapkan oleh Resto Ahwa dalam mempertahankan loyalitas pelanggan antara lain adalah:

1. Menjaga supaya kualitas dan menu masakannya tetap lezat dan baik sesuai selera pelanggan

2. Menjaga supaya pelayanan pegawai tetap ramah kepada pelanggan

3. Jika ada komplain maka ditanggapi dengan cepat

4. Memberikan umpan baik dan kotak kritik atau saran di resto sehingga pelanggan dapat mengungkapkan hasil survei.

5. Meningkatkan kualitas pelayanan dengan delivery order, misalnya dengan bekerja sama dengan Gojek maupun GoFood.

6. Meningkatkan kenyamanan dan fasilitas resto Ahwa

7. Melakukan transaksi dengan cepat dan efisien

8. Memberikan garansi atau jaminan kepada konsumen

9. Melayani dengan sigap dan cepat

10. Meningkatkan efektivitas komunikasi pemasaran dengan cara lebih menggalakkan promosi di media sosial.

11. Membentuk tim khusus untuk promosi melalui media sosial mengingat saat ini jaman Teknologi Informasi dapat meningkatkan penjualan dan kepuasan konsumen, misalnya melalui Instagram, WA, dll.

\section{Kesimpulan}

Strategi komunikasi bisnis yang dilakukan Resto Ahwa adalah komunikasi pribadi dua orang atau lebih memalui tatap muka dan tidak menggunakan sosial media karena masih banyak pelanggan kalangan orang tua yang masih kurang paham dengan adanya sosial media. Resto Ahwa menciptakan hubungan erat dengan pelanggan seperti mengembangkan program loyalitas seperti Promosi yang dilakukan adalah dengan memberikan diskon $10 \%$ pada hari Senin sampai Jumat, sedangkan hari Sabtu dan Minggu memberi diskon sebesar $10 \%$ bagi pelanggan yang menjadi member Restoran Ahwa. Cara untuk membuat pelanggan puas dan datang lagi ke Restoran Ahwa yaitu dengan suasana restoran dibuat senyaman mungkin 
mengunakan musik lagu mandarin dan membuka stand mainan dan makanan ringan di depan restoran serta mainan" untuk bagi orang tua yang membawa anak kecil agar anak mereka puas juga.

Kegiatan strategi komunikasi yang dilakukan Resto Ahwa menurutnya sudah tidak diperlukan lagi karena saat ini dia sudah berada di tingkat yang sudah baik, namun ada baiknya untuk terus meningkatkan strategi komunikasinya kepada orangorang yang memang belum mengenal restoran tersebut. Terlebih, Resto Ahwa saat ini sudah mengembangkan bisnisnya dengan membuka cabang yang terletak di Muara Karang yang juga cukup ramai pelanggan. Saran untuk penelitian ini adalah:

1. Sebaiknya Resto Ahwa dapat menggunakan media sosial untuk peningkatan strategi komunikasi agar lebih dikenal oleh masyarakat.

2. Selain itu dapat memberikan promo-promo dan diskon potongan harga bagi member.

\section{Ucapan Terima Kasih}

Penulis mengucapkan terima kasih kepada Restoran Ahwa yang telah bersedia menjadi narasumber dan waktunya wawancara dan informasi.

\section{Daftar Pustaka}

Bungin, Burhan. (2015). Metodologi Penelitian Kualitatif. Jakarta : Rajawali Pers. David, Fred R. (2011). Strategic Management, Buku 1. Edisi 12. Jakarta: Erlangga. Emzir. (2012). Metodologi Penelitian Kualitatif Analisis Data. Jakarta: PT. Raja. Grafindo Persada. '

Forbes, 2017, The World's Biggest Public Companies, Tersedia pada http://www.forbes.com/global2000/list/\#industry:Software\&programming

Hurriyati, Ratih. (2010). Bauran Pemasaran dan Loyalitas Konsumen. Bandung: ALFABETHA.

Kotler, Philip. (2014). Manajemen Pemasaran. Edisi Milenium, Jilid 2. Jakarta: PT Prenhallindo.

Kriyantono, Rachmat. (2010). Teknik praktis riset komunikasi: disertai contoh praktis riset media, public relation, advertising, komunikasi organisaso, komunikasi pemasaran. Jakarta: Kencana

Moleong, Lexy J. (2009). Metode Penelitian Kualitatif. Bandung: Remaja. Rosdakarya.

Ruben, Brent dan Lea P. Steward. (2014). Komunikasi dan Perilaku Manusia. Depok: PT. Raja Grafindo Persada

Ruslan, Arief. (2016). Animasi Perkembangan dan Konsepnya. Bogor: Ghalia. Indonesia

Soemanagara. (2014). Strategic Marketing Communication. Bandung : Alfabeta

Sutisna. (2013). Perilaku Konsumen Dan Komunikasi Pemasaran, Edisi Kedua. Bandung: Ramaja Rosdakarya.

Utami, Christina Widhya. (2013). Manajemen Ritel. Jakarta: Salemba Empat

Wenats, AG Eka. (2012). Integrated Marketing Communications Success Story. Jakarta : PT. Gramedia Pustaka Utama.

Widyahartono, Bob. (2009). Kongsi dan Spekulasi Jaringan Kerja Bisnis Cina. Jakarta: Pustaka Utama Grafiti. 